\title{
Offline and Online Channel Selection of Low-Carbon Supply Chain under Carbon Trading Market
}

\author{
Qiang Han $\mathbb{D}^{1},{ }^{1}$ Zhenlong Yang, ${ }^{1}$ Zheng Zhang, ${ }^{1}$ and Liang Shen ${ }^{2}$ \\ ${ }^{1}$ School of Management Science and Engineering, Shandong University of Finance and Economics, Jinan 250014, China \\ ${ }^{2}$ School of Public Finance and Taxation, Shandong University of Finance and Economics, Jinan 250014, China \\ Correspondence should be addressed to Qiang Han; qiang.han@sdufe.edu.cn
}

Received 18 November 2020; Revised 10 December 2020; Accepted 15 December 2020; Published 5 January 2021

Academic Editor: Ming Bao Cheng

Copyright (c) 2021 Qiang Han et al. This is an open access article distributed under the Creative Commons Attribution License, which permits unrestricted use, distribution, and reproduction in any medium, provided the original work is properly cited.

This paper investigates the low-carbon product manufacturer's different decision behavior in the offline traditional retail channel and online e-commerce channel when the carbon trading market has been established. The low-carbon product manufacturer is both in the carbon trading market and product market. In the former market, the manufacturer can gain profits by selling its emission quota. In the latter market, the manufacturer has two sales channel options, the traditional offline retailer and the online e-commerce platform. These two channels make two supply chains, the manufacturer-led offline one and the e-commerce platform-led online one. This paper combines the carbon trading market with the product market, formulates different Stackelberg game models, compares the manufacturer's decision under two channels and the impact of channels on the carbon emission, does sensitivity analysis, and verifies the conclusions with numerical examples. Our findings are (1) the establishment of the carbon market will help the manufacturer reduce its carbon emission, especially for those sensitive to the carbon price and those with too much emissions; (2) whether the manufacturer turns to the online channel depends on the consumers' sensitivity to the sales service, and consumers' attention will guide the way to the online mode; (3) which mode is conducive to carbon emission reduction relies on the product type: the e-commerce platform does well for daily necessities of mass production while the traditional channel is better for experience goods.

\section{Introduction}

Traditionally, the manufacturer used to sell products through the offline retail channel. Up to this day, with the rapid development of information and Internet technology, the birth of Amazon, Jingdong, and other e-commerce platforms opens up a more convenient option [1], which is transforming the consumers' shopping style with rapid momentum. In contrast with the traditional offline mode, the online one features convenient access to the product distinctively and the low cost to promote it. The manufacturer has to pay the sales revenue proportionally to the e-commerce platform when selling through it. The income ratio for the platform in the whole sales revenue is called the commission rate.

While the manufacturer provides consumers with various products, it also does with carbon emission, which will lead to an unpredictable influence on the globe. Data from NASA showed that the carbon dioxide level had reached the highest in the past 650,000 years (https://climate.nasa.gov/). So, consumers, with their increase in low-carbon awareness, are preferring low-carbon products. A poll from Accenture said that $72 \%$ of the respondents are willing to purchase lowcarbon products and pay a higher price (https://www. businessnewsdaily.com/15087-consumers-want-

sustainable-products.html). As a result, the manufacturer will invest more to carry out carbon emission reduction transformation and produce many low-carbon products. Thus, the manufacturer producing low-carbon products along with its upstream and downstream enterprises forms low-carbon supply chains [2].

To address the carbon emission problem, governments have tried many measures to promote low-carbon products. The EU initiated the carbon trading mechanism 
(https://www.thebalance.com/carbon-emissions-trading3305652), which gets accepted widely because of its marketization property and has been applied in China [3], Australia [4], New Zealand [5], and Europe [6]. The concept of carbon trading was originated from the UN Framework Convention on Climate Change and the Kyoto Protocol. The latter regards market mechanism as a new way to solve the problem of greenhouse gas emission reduction; that is, carbon emission right is regarded as one common commodity, and manufacturers are encouraged to save carbon emission quota through technological progress, which can be exchanged with other manufacturers. Carbon trading can internalize their original external cost, thus forming a forced mechanism to promote manufacturers to carry out emission reduction innovation.

The current research studies on carbon trading mostly focus on the traditional offline channel $[7,8]$. However, the e-commerce of the online channel is a more and more potential option for manufacturers to sell their products. Since manufacturers' ultimate goal is profit, they will weigh whether they can profit from the carbon trading market and which channel is more beneficial between the offline and online mode. We aim to answer the following questions:

(1) Under what conditions can manufacturers be profitable in the carbon trading market?

(2) Under what conditions can manufacturers turn to the online mode?

(3) What effects of the offline mode and online mode have on manufacturers' carbon emission?

Our study contributes to the related research by analyzing the supply chain decision after putting the manufacturer into both the carbon trading market and the low-carbon product market and applying the carbon trading into the online e-commerce supply chain mode. We formulate two Stackelberg game models to describe the low-carbon product manufacturer's decision behavior and compare the effect of different factors on its channel selection and carbon emission reduction. Results show that the carbon trading mechanism provides the manufacturer with a flexible carbon emission decision option and can guide it to reduce emissions consciously and effectively. However, the manufacturer's condition to gain profits is that the carbon market scale is located in a specific interval. From the view of channel selection, the commission rate plays an important role. It is concluded by combining the carbon trading and channel selection that which mode is conducive to the emission reduction depends on the product property sold by the manufacturer.

The rest of this paper is organized as follows. In Section 2, we review the related literature. In Section 3, we elaborate on the problem and give the necessary mathematical expression. Then, after low-carbon supply chain decision models are built in Section 4, we compare the results of different models and do managerial insights and sensitivity analysis in Section 5. In Section 6, we do numerical examples. And lastly, conclusions are made in Section 7.

\section{Literature Review}

Our research is closely related to two streams: carbon trading and supply chain channel selection.

2.1. Carbon Trading. Carbon trading is human beings' active strategy to deal with global climate change. Simulation results of Cheng et al. [9] showed the success of the carbon trading system to achieve emission reduction goal. The region starting the carbon trading system has reduced more carbon emission distinctively, which can also maintain sustainable economic development at the same time [10]. This was achieved by improving technology efficiency and transforming industry structure $[3,11,12]$.

However, Liu et al. [13] and Jiang et al. [14] thought there are still some challenges for the carbon trading market, for example, incomplete mechanism, inaccurate quota allocation, and the absence of real-time carbon price. Caparrós et al. [15] found that the emission trading system, though designed in its original intention to encourage manufacturers to reduce carbon emission by new technology, might result in manufacturers' production reduction. Jaraite and Di Maria [6] concluded based on Lithuanian data that EU's emission trading system did not help reduce emission at all.

Later, carbon emission in the supply chain was taken into research. Cheng et al. [16], after building the supply chain cooperative decision model combining carbon trading and carbon tax, showed that highly intense carbon policy does not mean manufacturers' emission reduction and lowcarbon production increase. Chen et al. [17] investigated how to regulate carbon trading in the case of uncertainty with stochastic programming. Benjaafar et al. [7] integrated carbon emission concern into the operation decision about procurement, production, and inventory management and studied the effect of the cooperation between multiple companies on emission reduction. Pang et al. [18] studied the influence of carbon price and consumers' environmental protection awareness on carbon emission in the supply chain and found clean manufacturers' unit carbon emission increased with the carbon trading price while other manufacturers stood opposite. Wang and Wu [19] considered the carbon trading behavior in the closed-loop supply chain and revealed that product recycle helped reduce carbon emission but high initial carbon emission did not. Xu et al. [20] studied decision and coordination in the dual-channel supply chain under cap-and-trade, suggesting that governments should achieve coordinated development of economy and environment by starting carbon trading. Xu et al. [8] explored the emission reduction decision in the make-to-order supply chain and concluded that manufacturers could adopt green technology to reduce unit carbon emission and the optimal production would not be affected by the increase in carbon price.

2.2. Supply Chain Channel Selection. Product sales can be divided into single channel, multichannel, and omnichannel [21]. However, dual-channel, one mode among multichannels, is mostly focused. Dual-channel means the 
addition of direct sales or other channel besides the traditional retail, in which consumers determine their purchase channel based on the product price and service level [22-24]. After considering the supply chain with the traditional retail channel and direct online channel, in which the manufacturer provides customized product online while provides standard products offline, Batarfi et al. [25] found that the customized product sales through the extra online channel could increase its profit but also bring conflict. Yoo and Lee [26] discovered that the online channel did not bring much lower price and much higher consumers' welfare necessarily. Bernstein et al. [27] also found that new channel did not mean better returns when analyzing the feasibility for the retailers in the transition from offline sales to mixed modes.

There are two special ones, BOPS (buy online and pick up in store) and $\mathrm{O} 2 \mathrm{O}$ (online to offline) in the dual-channel mode. Gao and Su [28] argued not all goods suit the BOPS mode, even for regular customers, but it can attract much more new customers. Gallino and Moreno [29] found that the BOPS mode would lead to the decrease in online sales and the increase in store sales. Chen et al. [30] analyzed the pricing strategy of the offline mode and online mode in the mixed dual-channel and the influence of supply chain power structure on pricing.

In different modes, it is vital whether consumers accept them. Jia [31] investigated two e-commerce modes, selfowned platform and others-owned platform, and came to a conclusion that the channel service level and the sensitivity of consumers to channel service would influence the supply chain desicion. Li et al. [32] compared the relation between direct online sales and brand stores and revealed that if the brand store was established first, the manufacturer might introduce the direct online mode; otherwise, it might not. Zhang et al. [33] showed that the optimal channel is pure offline mode, dual-channel mode, and pure online mode, respectively, corresponding to consumers' acceptance degree of the online mode, low, medium, and high. Lu and Niu [34] found that the channel acceptance played an important role in affecting equilibrium price when then the traditional retail channel and e-commerce channel were compared.

Based on the above literature review, most research about carbon trading focuses on the offline supply chain channel, while the e-commerce is rarely touched. However, the online sale has been trending. So, we should extend the carbon trading from the offline mode to online one. From the view of channel selection, the offline mode, together with the online mode, will result in the free rider problem with high probability, which will decrease the supply chain profit [35]. And, multiple channels are easy to cause channel conflict [36]. In the supply chain under the carbon trading market, the manufacturer, as the primary source of carbon emission, will take into account the revenue from carbon emission and product sales together. Thus, this paper investigates the channel selection problem between the offline and online modes from the manufacturer's perspective and analyzes which channel is conducive to carbon emission reduction under the carbon trading background.

\section{Problem Description and Basic Relations}

3.1. Problem Description. Suppose there is a low-carbon product manufacturer located in the region where has started a carbon trading system. So, the manufacturer is contained in the carbon trading market and product market.

The manufacturer brings carbon emissions during production. Then, it will make process improvements to reduce emissions. Afterward, the manufacturer can attract consumers preferring low-carbon products and sell its carbon emission quota to gain profit in the carbon trading market.

The manufacturer can sell its product through the traditional offline retail channel or online e-commerce platform channel. What is different from the offline mode is that the manufacturer has to pay some proportional sales revenue to the platform as the feedback for providing the sales channel in the online mode [37]. The ratio of the income for the platform in the whole sales revenue is called commission rate.

Therefore, we will investigate two supply chains, the supply chain consisting of one low-carbon manufacturer and one retailer and that consisting of one low-carbon manufacturer and one e-commerce platform (abbreviated as the platform if no ambiguity exists). In different channels, the manufacturer has contrasting status [38]: it is the leader in the product-oriented offline mode while it is the follower in the channel-oriented online one [39]. The manufacturer's profit comes from carbon trading and product sales.

3.2. Mathematical Notations and Relations of the Supply Chain. In this subsection, we provide mathematical notations and relations corresponding to the supply chain member. Some notations are listed in Table 1, which will be used frequently in this paper.

\section{(i) Manufacturer}

The manufacturer sells its product at the unit price of $P$ to consumers in the e-commerce platform and wholesale price of $P_{w}$ in the offline mode to the retailer.

It is obvious that $E<\widehat{E}$. According to Nair and Narasimhan's research [40], the manufacturer's cost for process improvements is functioned as

$$
C_{m}(E)=\alpha(\widehat{E}-E)^{2} .
$$

(ii) E-commerce platform

According to Wu's research [41], the platform's cost to serve consumers can be formulated as

$$
C_{p}\left(L_{p}\right)=\beta L_{p}^{2}
$$

(iii) Retailer

To gain much revenue, the retailer will try its best to sell products. Then, its sales cost can be expressed as [41] 
TABLE 1: Mathematical notations.

\begin{tabular}{lr}
\hline Notations & Meaning \\
\hline$C$ & The manufacturer's unit production cost \\
$P_{w}$ & Unit offline wholesale price \\
$P$ & Unit online retail price \\
$P_{r}$ & Unit offline retail price \\
$P_{c}$ & Carbon price in the carbon trading market \\
$\widehat{E}$ & The manufacturer's carbon emission before process improvements \\
$E$ & The manufacturer's carbon emission after process improvements \\
$\alpha(\alpha>0)$ & Elastic coefficient of carbon emission reduction cost \\
$\beta(\beta>0)$ & Elastic coefficient of service cost \\
$\gamma(\gamma>0)$ & Promotion effort level coefficient \\
$\theta(0<\theta<1)$ & Commission rate \\
$L_{p}$ & The platform's sales service level \\
$L_{r}$ & The retailer's promotion effort level \\
$Q$ & Sensitivity coefficient to the product price \\
$d_{1}$ & Sensitivity coefficient to the product service \\
$d_{2}$ & Carbon market scale \\
$\Phi$ & Sensitivity coefficient to the carbon price \\
$\varphi$ &
\end{tabular}

$$
C_{r}\left(L_{r}\right)=\gamma L_{r}^{2}
$$

As well known, more cost has to be invested in the offline service than the online one because of the channel difference in the amount of target audience and the convenience of promotion. Therefore, we suppose $\gamma>\beta$.

3.3. Demand Functions for Different Markets. Demand functions of different markets are given as follows:

(i) Offline channel product market

In the offline mode, the product demand is dominated by the product price and retailer's service. The demand function of the product can be formulated as $[37,39]$

$$
q_{1}\left(P_{r}, L_{r}\right)=Q-d_{1} P_{r}+d_{2} L_{r}
$$

To let the following gaming process hold, we suppose $4 d_{1} \gamma>d_{2}^{2}, 4 d_{1} \beta>d_{2}^{2}$.

(ii) Online channel product market

In the online mode, the product demand is dominated by the product price and platform's service. The demand function can be expressed as $[37,39]$

$$
q_{2}\left(P, L_{p}\right)=Q-d_{1} P+d_{2} L_{p}
$$

(iii) Carbon trading market

The carbon emission reduction can increase the low-carbon product sales after consumers' environmental awareness rises and helps the manufacturer profit from the carbon trading market. As the trading is concerned, carbon emission quota can be treated as common products. Similar to the inverse demand function of common products that of $P_{c}$ with the carbon emission can be functioned as [7]

$$
P_{c}(E)=\Phi-\varphi E,
$$

where $\varphi$ is used to measure the influence of emissions on the carbon price. Positive $P_{c}$ means that the manufacturer can gain profit because of its low-carbon emission, while negative $P_{c}$ indicates that the manufacturer has to pay cost for its high emission. Obviously, we have $\Phi-\varphi \widehat{E}<0$. Otherwise, manufacturers with too much emissions cannot be punished so that they do not have initiative to reduce them, which is contrary to the original intention of opening the carbon trading market.

Also, let $e_{c}$ denote the carbon emission per unit product. Then,

$$
e_{c}=\frac{E}{q}
$$

where $q$ is the product demand. The smaller $e_{c}$ is, the better the low-carbon level of the product is.

\section{Supply Chain Decision Models under Carbon Trading Market}

In this section, we formulate two supply chain game models corresponding to the manufacturer's sales channels.

4.1. Model I: Offline Channel. In the traditional offline supply chain channel, the product demand function is 


$$
q_{1}\left(P_{r}, L_{r}\right)=Q-d_{1} P_{r}+d_{2} L_{r}
$$

The manufacturer's profit from product market is

$$
\begin{aligned}
I_{m 1 p}\left(P_{w}, P_{r}, L_{r}\right) & =\left(P_{w}-C\right) q_{1} \\
& =\left(P_{w}-C\right)\left(Q-d_{1} P_{r}+d_{2} L_{r}\right) .
\end{aligned}
$$

The manufacturer's profit from carbon trading market is

$$
I_{m 1 c}(E)=P_{c} E-C_{m}(E) .
$$

Thus, the manufacturer's total profit is

$$
\begin{aligned}
\Pi_{m 1}\left(P_{w}, P_{r}, L_{r}, E\right)= & I_{m 1 p}+I_{m 1 c} \\
= & \left(P_{w}-C\right)\left(Q-d_{1} P_{r}+d_{2} L_{r}\right) \\
& +(\Phi-\varphi E) E-\alpha(\widehat{E}-t E)^{2} .
\end{aligned}
$$

The retailer's profit is

$$
\begin{aligned}
\Pi_{r 1}\left(P_{w}, P_{r}, L_{r}\right) & =\left(P_{r}-P_{w}\right) q_{1}-C_{r}\left(L_{r}\right) \\
& =\left(P_{r}-P_{w}\right)\left(Q-d_{1} P_{r}+d_{2} L_{r}\right)-\gamma L_{r}^{2},
\end{aligned}
$$

and the supply chain's profit is

$$
\begin{aligned}
\Pi_{1}\left(P_{r}, L_{r}, E\right)= & \Pi_{m 1}\left(P_{w}, P_{r}, L_{r}, E\right)+\Pi_{r 1}\left(P_{w}, P_{r}, L_{r}\right) \\
= & \left(P_{r}-C\right)\left(Q-d_{1} P_{r}+d_{2} L_{r}\right) \\
& +(\Phi-\varphi E) E-\alpha(\widehat{E}-t E)^{2}-\gamma L_{r}^{2} .
\end{aligned}
$$

During the gaming process, the manufacturer and the retailer form a Stackelberg game, with the former as the leader and the latter as the follower. The manufacturer determines its wholesale price $P_{w}$ and carbon emission level $E$; then, the retailer determines its retail price $P_{r}$ and service level $L_{r}$. Their gaming problem can be formulated as

$$
\begin{array}{ll}
\max _{P_{w}, E} & \Pi_{m 1}\left(P_{w}, P_{r}, L_{r}, E\right)=\left(P_{w}-C\right)\left(Q-d_{1} P_{r}+d_{2} L_{r}\right) \\
& +(\Phi-\varphi E) E-\alpha(\widehat{E}-t E)^{2} \\
\text { s.t. } \quad & \max _{P_{r}, L_{r}} \Pi_{r 1}\left(P_{w}, P_{r}, L_{r}\right)=\left(P_{r}-P_{w}\right)\left(Q-d_{1} P_{r}+d_{2} L_{r}\right) \\
& -\gamma L_{r}^{2} .
\end{array}
$$

Thus, the optimal decision of this model is obtained as in Conclusion 1.

Conclusion 1. When the manufacturer sells its low-carbon product through the offline channel, the optimal decision is

$$
\begin{aligned}
& P_{w}^{*}=\frac{C}{2}+\frac{Q}{2 d_{1}}, \\
& E_{1}^{*}=\frac{2 \widehat{E} \alpha+\Phi}{2(\alpha+\varphi)} \\
& P_{r}^{*}=\frac{C}{2}+\frac{Q}{2 d_{1}}+\frac{\left(Q-C d_{1}\right) \gamma}{4 d_{1} \gamma-d_{2}^{2}}, \\
& L_{r}^{*}=\frac{d_{2}\left(Q-C d_{1}\right)}{8 d_{1} \gamma-2 d_{2}^{2}}, \\
& \Pi_{m 1}^{*}=\frac{\left(Q-C d_{1}\right)^{2} \gamma}{2\left(4 d_{1} \gamma-d_{2}^{2}\right)}+\frac{\Phi^{2}+4 \alpha \widehat{E}(\Phi-\varphi \widehat{E})}{4(\alpha+\varphi)}, \\
& \Pi_{r 1}^{*}=\frac{\left(Q-C d_{1}\right)^{2} \gamma}{4\left(4 d_{1} \gamma-d_{2}^{2}\right)} \\
& \Pi_{1}=\frac{3\left(Q-C d_{1}\right)^{2} \gamma}{4\left(4 d_{1} \gamma-d_{2}^{2}\right)}+\frac{\Phi^{2}+4 \alpha \widehat{E}(\Phi-\varphi \widehat{E})}{4(\alpha+\varphi)}, \\
& q_{1}=\left(Q-C d_{1}\right) d_{1} \gamma
\end{aligned}
$$


See Appendix A for the proof of Conclusion 1.

4.2. Model II: Online Channel. In the online e-commerce supply chain channel, the product demand function is

$$
q_{2}\left(P, L_{p}\right)=Q-d_{1} P+d_{2} L_{p}
$$

The manufacturer's profit from the product market is

$$
\begin{aligned}
I_{m 2 p}\left(P, L_{p}\right) & =(P-\theta P-C) q_{2} \\
& =(P-\theta P-C)\left(Q-d_{1} P+d_{2} L_{p}\right), \quad 0<\theta<1 .
\end{aligned}
$$

The manufacturer's profit from the carbon trading market is

$$
I_{m 2 c}(E)=P_{c} E-C_{m}(E) .
$$

Thus, the manufacturer's total profit is

$$
\begin{aligned}
\Pi_{m 2}\left(P, L_{p}, E\right)= & I_{m 2 p}+I_{m 2 c} \\
= & (P-\theta P-C)\left(Q-d_{1} P+d_{2} L_{p}\right) \\
& +(\Phi-\varphi E) E-\alpha(\widehat{E}-t E)^{2} .
\end{aligned}
$$

The e-commerce platform's profit is

$\Pi_{p 2}\left(P, L_{p}\right)=\theta P q-C_{p}\left(L_{p}\right)=\theta P\left(Q-d_{1} P+d_{2} L_{p}\right)-\beta L_{p}^{2}$, and the supply chain's profit is

$$
\begin{aligned}
\Pi_{2}\left(P, L_{p}, E\right)= & \Pi_{m 2}\left(P, L_{p}, E\right)+\Pi_{p 2}\left(P, L_{p}\right) \\
= & (P-C)\left(Q-d_{1} P+d_{2} L_{p}\right) \\
& +(\Phi-\varphi E) E-\alpha(\widehat{E}-t E)^{2}-\beta L_{p}^{2} .
\end{aligned}
$$

Their decision process forms a Stackelberg game, with the platform as the leader and the manufacturer as the follower, in which the platform gives its service level $L$ first and then the manufacturer decides its sale price $P$ and carbon emission level $E$. Their gaming problem can be formulated as

$$
\begin{array}{ll}
\max _{P, E} \quad \Pi_{m 2}\left(P, L_{p}, E\right)=(P-\theta P-C)\left(Q-d_{1} P+d_{2} L_{p}\right) \\
& +(\Phi-\varphi E) E-\alpha(\widehat{E}-t E)^{2} \\
\text { s.t. } \quad \max _{L_{p}} \Pi_{p 2}\left(P, L_{p}\right)=\theta P q-C_{p}\left(L_{p}\right) \\
= & \theta P\left(Q-d_{1} P+d_{2} L_{p}\right)-\beta L_{p}^{2} .
\end{array}
$$

Similar to the proof of Conclusion 1, we have the following conclusion.

Conclusion 2. When the manufacturer sells its low-carbon product through the online e-commerce platform channel, the optimal decision is

$$
\begin{aligned}
P^{*} & =\frac{4 Q \beta(1-\theta)+C\left(4 d_{1} \beta-d_{2}^{2} \theta\right)}{2(1-\theta)\left(4 d_{1} \beta-d_{2}^{2} \theta\right)}=\frac{2 Q \beta}{4 d_{1} \beta-d_{2}^{2} \theta}+\frac{C}{2(1-\theta)}, \\
E_{2}^{*} & =\frac{2 \widehat{E} \alpha+\Phi}{2(\alpha+\varphi)}, \\
L_{p}^{*} & =\frac{d_{2} Q \theta}{4 d_{1} \beta-d_{2}^{2} \theta}, \\
\Pi_{m 2}^{*} & =\frac{d_{1}\left[4 Q \beta(1-\theta)-C\left(4 d_{1} \beta-d_{2}^{2} \theta\right)\right]^{2}}{4(1-\theta)\left(4 d_{1} \beta-d_{2}^{2} \theta\right)^{2}}+\frac{\Phi^{2}+4 \alpha \widehat{E}(\Phi-\varphi \widehat{E})}{4(\alpha+\varphi)}, \\
\Pi_{p 2}^{*} & =\frac{\theta\left[4 Q^{2} \beta(1-\theta)^{2}-C^{2} d_{1}\left(4 d_{1} \beta-d_{2}^{2} \theta\right)\right]}{4(1-\theta)^{2}\left(4 d_{1} \beta-d_{2}^{2} \theta\right)}, \\
\Pi_{2} & =\frac{4 Q^{2} \beta^{2} d_{1}(1-\theta)}{\left(4 d_{1} \beta-d_{2}^{2} \theta\right)^{2}}+\frac{d_{1} C^{2}(1-2 \theta)}{4(1-\theta)^{2}}+\frac{\left(Q \theta-2 d_{1} C\right) Q \beta}{4 d_{1} \beta-d_{2}^{2} \theta}+\frac{\Phi^{2}+4 \alpha \widehat{E}(\Phi-\varphi \widehat{E})}{4(\alpha+\varphi)}, \\
q_{2} & =\frac{2 d_{1} \beta}{\left(4 d_{1} \beta-d_{2}^{2}\right)+(1-\theta) d_{2}^{2}} Q-\frac{C d_{1}}{2(1-\theta)} .
\end{aligned}
$$




\section{Result Analysis and Managerial Insights}

Conclusion 3. The manufacturer has the same emission reduction level in Model I as in Model II.

It is shown from Conclusion 3 that the production, only related to the manufacturer who assumes the emission reduction cost and obtains the carbon trading revenue by itself, is not associated with the offline retailer in the traditional supply chain and the online platform in the e-commerce supply chain. Therefore, the carbon emission reduction level is only decided by the manufacturer, and the product sale will be crucial in the manufacturer's decision.

Conclusion 4. The establishment of the carbon market helps the manufacturer reduce its emission. The amount of emission reduction increases with $\widehat{E}$ and $\varphi$ while decreases with $\Phi$ and $\alpha$.

See Appendix B for the proof of Conclusion 4.

Conclusion 4 tells us that the establishment of the carbon trading market for manufacturers is feasible and conducive to emission reduction. The market mechanism creates a suitable environment for manufacturers to actively reduce emissions; this mechanism will drive the manufacturer with large initial carbon emission to reduce much more emission for getting more trading space; manufacturers sensitive to the carbon price also tend to reduce more emission so that it does not have to cost much to get emission permit and can earn revenue by selling its emission quota. In fact, there are also factors against emission reduction. When the current carbon market scale is rising, it means that the corresponding industry is facing many difficulties in reducing emissions. As a result, this manufacturer's emission will rise more or less. If the elastic coefficient of carbon emission reduction cost increases, it suggests that the current unit emission reduction cost has increased so that excessive emission reduction will make the manufacturer's cost go up.

Conclusion 5. The manufacturer has negative profit in the carbon market if

$$
0<\frac{\Phi}{\widehat{E}}<2 \alpha\left(\sqrt{\frac{1+\varphi}{\alpha}}-1\right),
$$

and positive if

$$
2 \alpha\left(\sqrt{\frac{1+\phi}{\alpha}}-1\right)<\frac{\Phi}{\widehat{E}}<\varphi .
$$

See Appendix C for the proof of Conclusion 5 .

Conclusion 5 indicates that if the carbon market scale is too small and there is no enough demand to encourage carbon trading, the manufacturer cannot sell its carbon emission quota and get profitable from the carbon market. Therefore, the manufacturer's condition to obtain profit is the carbon market must rise to a critical scale, which is $2 \alpha(\sqrt{((1+\phi) / \alpha)}-1)$ times of the manufacturer's emission. Only above this critical scale dose, the manufacturer has the desire to reduce emission. This critical scale multiple is decided by the elastic coefficient of carbon emission reduction cost $\alpha$ and the sensitivity coefficient to the carbon price $\varphi$.

Conclusion 6. In the e-commerce mode, the product price $P^{*}$, the platform's service level $L_{p}^{*}$ and profit $\Pi_{2}^{*}$, and the supply chain's profit $\Pi_{2}$ all increase with the commission rate $\theta$. The manufacturer's profit rises with the increase in the commission rate if $d_{2}^{2}<2 d_{1} \beta$ and rises up then falls down if $d_{2}^{2}>2 d_{1} \beta$.

See Appendix D for the proof of Conclusion 6 .

Conclusion 6 shows that if occupying a higher proportion of profit in the supply chain, the platform can help add its profit and have subsequent desire to improve its service level to attract more consumers, which is conducive to the rise of the supply chain's profit. However, this affects the manufacturer's profit. When the platform's elastic coefficient of service cost $\beta$ is relatively small $\left(d_{2}^{2}>2 d_{1} \beta\right)$, the manufacturer still has space to increase profit, but most profits are eventually been possessed by the platform with the rise of commission rate. It also can be known from the proof that the difference between $d_{2}^{2}$ and $2 d_{1} \beta$ decides the manufacturer's space to increase profit. If this difference is really large, the manufacturer has enough space to maintain growth; otherwise, the space will be narrow. If $\beta$ is quite large $\left(d_{2}^{2}<2 d_{1} \beta\right)$, the platform will try to grab profit in the supply chain to offset its cost for improving the service level, which makes the manufacturer's profit fall down with the increase in the commission rate.

The manufacturer will raise product price to secure its profit, expecting that the loss caused by unfair profit allocation could be made up by high price and sales. This demonstrates the manufacturer's awkward situation under the case led by the platform; after the price is raised, the supply chain's whole profit rises, but its own part is still on the decrease.

It follows from the above conclusion that when $\theta$ is close to 1 , the product price $P$ will approach infinity. This is produced because the platform excessively occupies the sales income while the manufacturer tends to increase the price for expected profit. This will results in the negative $q_{2}$. Thus, to ensure the research practical, we reset the range of $\theta$. Since

$$
q_{2}=\frac{2 d_{1} \beta}{\left(4 d_{1} \beta-d_{2}^{2}\right)+(1-\theta) d_{2}^{2}} Q-\frac{C d_{1}}{2(1-\theta)}>0,
$$

we have the following conclusion.

Conclusion 7. $0<\theta<\max \left\{\left(\left(4 Q \beta-C d_{1} \beta\right) /\left(4 Q \beta-C d_{2}^{2}\right)\right), 1\right\}$.

Conclusion 8. In the product market, the manufacturer has more profit than the e-commerce platform if

$$
0<\theta<\frac{4 d_{1} \beta-2 \sqrt{d_{1} \beta\left(4 d_{1} \beta-d_{2}^{2}\right)}}{d_{2}^{2}}
$$

and the platform has more if 


$$
\frac{4 d_{1} \beta-2 \sqrt{d_{1} \beta\left(4 d_{1} \beta-d_{2}^{2}\right)}}{d_{2}^{2}}<\theta<1 .
$$

See Appendix E for the proof of Conclusion 8 .

Conclusion 9. The manufacturer's criterion to sell online is as follows:

(1) $\theta \in\left(0, \min \left\{\theta_{2}, 1\right\}\right)$, if $d_{2}^{2}<2 d_{1} \gamma$.

(2) $\theta \in\left(\theta_{1}, \min \left\{\theta_{2}, 1\right\}\right)$, if $d_{2}^{2} \geq 2 d_{1} \gamma$, where

$$
\begin{aligned}
\theta_{1} & =\frac{8 d_{1} \beta\left[(\beta+\gamma) d_{2}^{2}-4 d_{1} \beta \gamma\right]-\sqrt{\Delta}}{2 \gamma d_{2}^{4}}, \\
\theta_{2} & =\frac{8 d_{1} \beta\left[(\beta+\gamma) d_{2}^{2}-4 d_{1} \beta \gamma\right]+\sqrt{\Delta}}{2 \gamma d_{2}^{4}}, \\
\Delta & =64 d_{1}^{2} \beta^{2}\left[(\beta+\gamma) d_{2}^{2}-4 d_{1} \beta \gamma\right]^{2}-32 d_{1} d_{2}^{4} \beta^{2} \gamma\left(d_{2}^{2}-2 d_{1} \gamma\right) .
\end{aligned}
$$

See Appendix F for the proof of Conclusion 9.

Conclusion 9 implies that whether the manufacturer selects the online e-commerce mode depends on the sensitivity coefficient to the product price and that to the product service. The change of these two coefficients will affect the suitable commission interval for the manufacturer's channel decision. When the sensitivity coefficient to the product service is small, the service level affects the sales little, so the effect of the platform on the revenue is small. The manufacturer's expectation to gain more profit than offline and occupy more sales revenue can be achieved when the commission rate is low. Conversely, if the service level affects sales greatly, the platform should be expected to provide better service for attracting more consumers. However, the essential condition for the platform willing to cooperate is obtaining much more revenue. Therefore, the commission rate should be raised in this case.

Conclusion 10. The manufacturer's carbon emission per unit product through the online channel is lower than that through the offline one if

$$
\gamma<\frac{1}{2 d_{1}}
$$

The manufacturer's carbon emission per unit product through the offline channel is lower than that through the online one if

$$
\gamma>\frac{2 \beta}{4 d_{1} \beta-d_{2}^{2}} .
$$

The manufacturer's carbon emission per unit product through the offline channel is first lower and then higher than that through the online one if

$$
\frac{1}{2 d_{1}} \leq \gamma \leq \frac{2 \beta}{4 d_{1} \beta-d_{2}^{2}} .
$$

See Appendix G for the proof of Conclusion 10 .

Conclusion 10 reveals that the online mode does not necessarily result in better carbon emission per unit product than the offline one. It depends. If both $\gamma$ and $\beta$ are small, the e-commerce platform can sell more products. These are products with low sales cost, for example, goods involving daily life. If $\gamma>\left(2 \beta /\left(4 d_{1} \beta-d_{2}^{2}\right)\right)$, the proof shows that the offline sales have surpassed the online one greatly. This corresponds to goods needing much offline experience. If $\left(1 /\left(2 d_{1}\right)\right) \leq \gamma \leq\left(2 \beta /\left(4 d_{1} \beta-d_{2}^{2}\right)\right)$, the online product sales is first lower then higher than the offline one with the increase in the commission rate in the e-commerce platform mode. This demonstrates that for goods in between, we can rely on the platform's advantage in customer acquisition, improving the service level after the commission rate rises, to stimulate consumers' demand for the low-carbon product. In this way, the platform's advantage is put to fair use, which can play a positive role in reducing carbon emission.

\section{Numerical Examples}

In this section, we elaborate on the above conclusions with numerical examples. Suppose $Q=100000, C=3, \widehat{E}=35$, $\Phi=300, \phi=10, \alpha=5, \beta=2, \gamma=5, \theta=0.4, d_{1}=2$, and $d_{2}=3$.

6.1. Carbon Emission Reduction Analysis. The manufacturer's carbon emission reduction relation affected by other factors is shown in Figure 1.

It can be known from Figure 1 that the manufacturer's amount of carbon emission reduction monotonously increases with the initial emission amount and the sensitivity coefficient to the carbon price and monotonously decreases with the carbon market scale and the elastic coefficient of carbon emission reduction cost. The factors influencing the manufacturer's emission reduction behavior include two types, internal and external. Internal factors are initial emission amount and elastic coefficient of carbon emission reduction cost, while the external ones are carbon market scale and sensitivity coefficient to the carbon price. In fact, there is always one factor conducive to emission reduction and one adverse to that, no matter for internal factors and external ones. Once the initial emission amount and carbon market scale are settled down, the significant influencing factors turn to be the sensitivity coefficient to the carbon price (external and conducive to) and elastic coefficient of carbon emission reduction cost (internal and adverse to). Therefore, the governmental supervision department should promote manufacturers' sensitivity to carbon price by moderately strengthening carbon emission control, which can guide manufacturers actively to speeding up emission reduction. Meanwhile, government subsidies and other measures that lower manufacturers' emission reduction cost are also useful in boosting their initiative. 


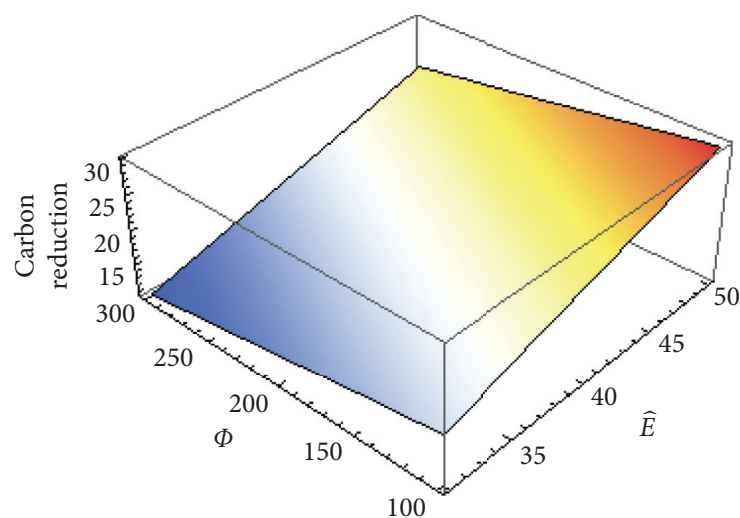

(a)

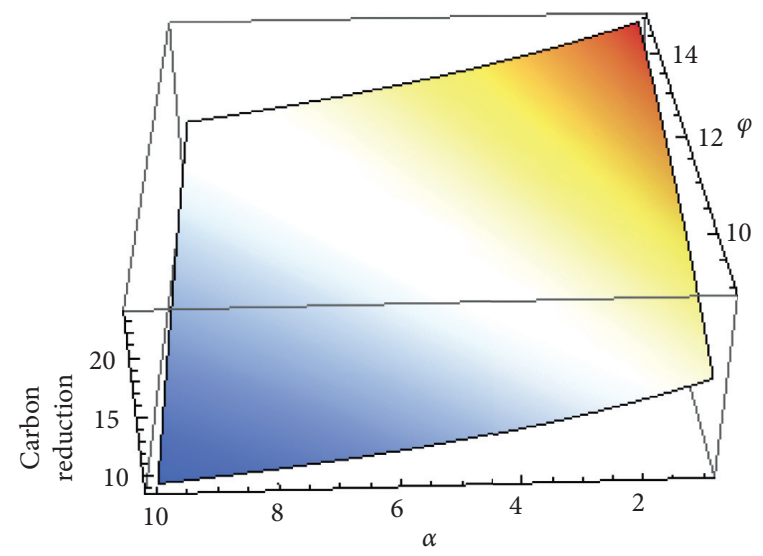

(b)

Figure 1: The manufacturer's carbon emission reduction: (a) change with $\Phi$ and $\widehat{E}$; (b) change with $\alpha$ and $\phi$.

6.2. Analysis on the Manufacturer's Profit from Carbon Market. The manufacturer's profit change in the carbon market affected by other factors is depicted in Figure 2.

After making Figure 2(a) with $(\Phi / \widehat{E})$ as the independent variable, we can find that the manufacturer's profit from the carbon market is 0 when $(\Phi / \widehat{E})=7.32$, negative when $(\Phi / \widehat{E})<7.32$, and positive only when $(\Phi / \widehat{E})>7.32$. However, the constraint, $(\Phi / \widehat{E})<\varphi=10$, actually leaves very narrow space for the manufacturer to gain positive profit, which is demonstrated more distinctively in Figure 2(b). Based on the current parameters' value, only the blue area above the green plane is where the manufacturer will be active in the carbon trading market. Flexibly, we could expand the manufacturer's profit area by enlarging the sensitivity coefficient to the carbon price. Consistent with the analysis in Section 6.1, this highlights the significance of strengthening carbon emission control by governmental supervision departments because the governmental supervision to promote the manufacturer's sensitivity to carbon price is a "kill two birds with one stone" strategy, not only stimulating the emission reduction but also further helping the manufacturer gain profit, which will form a virtuous circle.

6.3. Profit Analysis of Manufacturer and E-Commerce Platform in Online Mode. The influence of the commission rate on the e-commerce supply chain and its members is displayed in Figure 3.

As can be seen from Figure 3, with the increase in the commission rate, the manufacturer's profit experiences a significant decline after a slight rise, while profits of the platform and the supply chain rise obviously (Figure 3(a)). During the cooperation between multiple parties, the platform relies on its leading status to set the commission rate. When the platform raises the commission rate to add its profit, the good result is that enough funds can ensure its ability to improve the service level (Figure 3(b)), but the bad result is that this move lowers the manufacturer's profit, so the latter has to defend its interest by trying to raise the product price (Figure 3(c)). The rise of product price is the adverse factor for product sales; however, consumers clearly prefer the utility produced by better service level, so the sales can still mount up even though the manufacturer raises the price (Figure 3(d)). This also reflects how important the sales service is in the e-commerce supply chain, which is critical to attract consumers. The reason that the increase in the manufacturer's profit is not easy to detect at the beginning, combing the proof of Conclusion 6 , lies in that $d_{2}^{2}$ and $2 d_{1} \beta$ satisfy $d_{2}^{2}>2 d_{1} \beta$, but the difference between $d_{2}^{2}$ and $2 d_{1} \beta$ is too small, which squeezes the manufacturer's space to increase profit so that brief profit rise is soon ruined by the increase in the commission rate.

6.4. Analysis on Whether the Manufacturer Selects Online Mode. Based on the given parameters' value, we make Figure 4(a), showing the change of the manufacturer's profit in the online mode and offline mode with the commission rate. In Figure $4(\mathrm{a}), d_{2}^{2}<2 d_{1} \gamma$ holds. In order to contrast, we reset $\beta=3.4$ and $d_{2}=5$ so that $d_{2}^{2} \geq 2 d_{1} \gamma$ holds, and we make Figure 4(b) similarly.

It can be seen from Figure 4 (a) that if $d_{2}^{2}<2 d_{1} \gamma$, the manufacturer gets much more profit from the online mode than offline mode when $0<\theta<0.81$. Figure 4 (b) demonstrates that if $d_{2}^{2} \geq 2 d_{1} \gamma$, this case holds when $0.30<\theta<1$. Relatively speaking, when the effect of the service level on the sales is not large (Figure 4(a)), the manufacturer's profit experiences continual fall after slight rise with the increase in commission rate, which is consistent with Figure 3(a). Figure 3(a) tells that the critical point of commission rate is 0.6. The manufacturer has more profit than the platform when the commission rate is smaller than 0.6 ; on the contrary when that is larger than 0.6. Thus, after the commission rate goes beyond 0.6 , although the manufacturer's profit starts smaller than the platform, its profit is still higher than the offline mode until the commission rate reaches 0.81 . When the effect of the service level on the sales is large (Figure $4(\mathrm{~b})), d_{2}^{2} \geq 2 d_{1} \gamma$, and the difference between $d_{2}^{2}$ and $2 d_{1} \beta$ is big, the manufacturer is given enough space to raise profit. As can be seen, the increasing interval has been extended to $\theta<0.9$. 


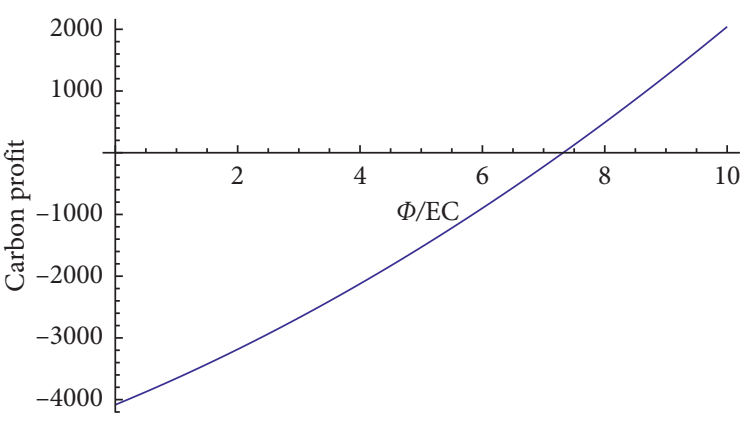

(a)

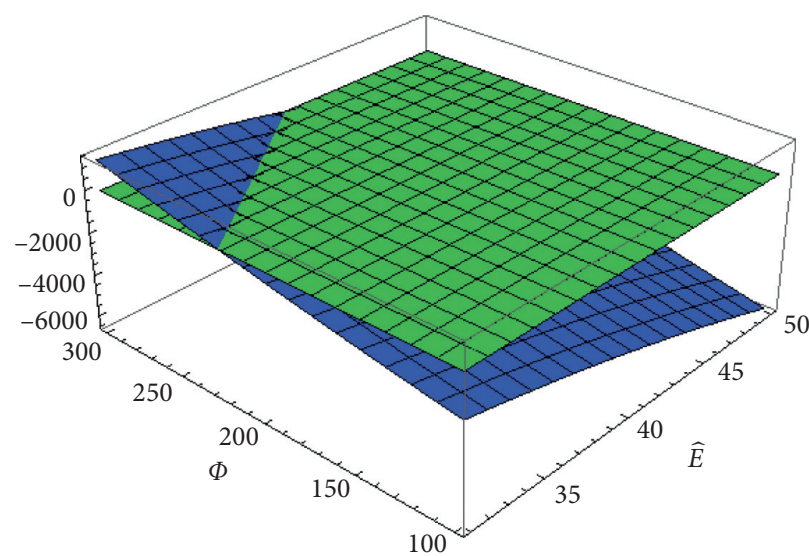

(b)

Figure 2: The manufacturer's profit from the carbon market: (a) change with $(\Phi / \phi)$; (b) change with $\Phi$ and $\widehat{E}$.

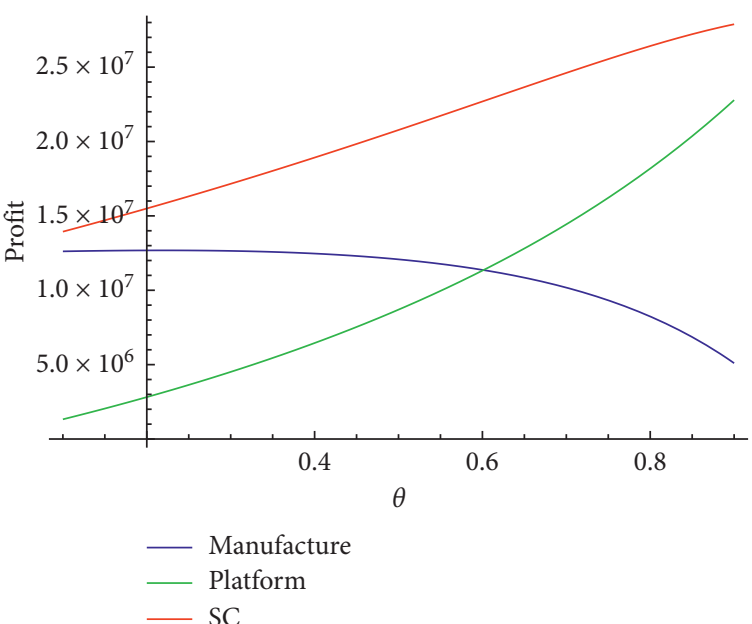

(a)

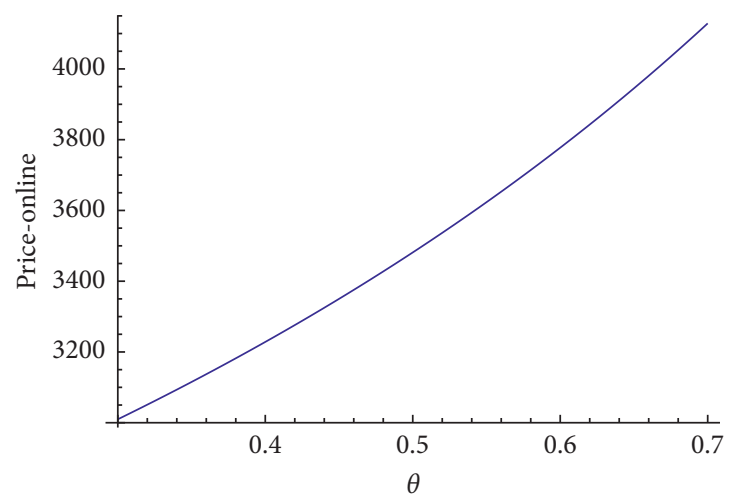

(c)

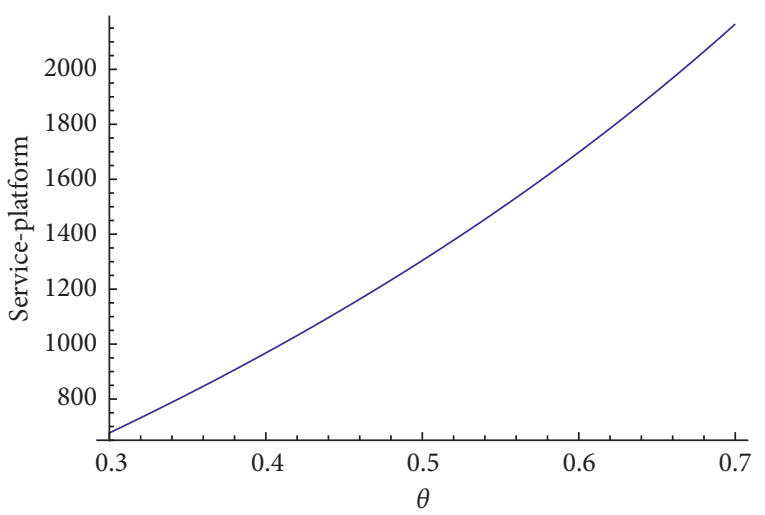

(b)

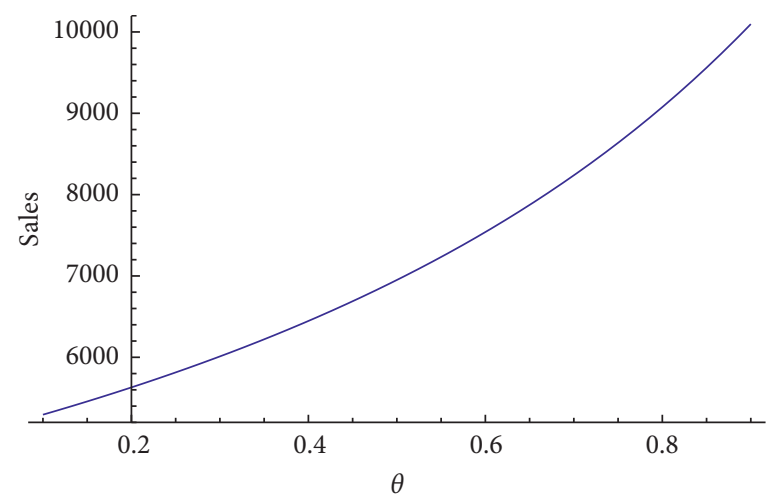

(d)

FIGURE 3: Changes of the supply chain's decision with $\theta$ in the online mode: (a) change in profits; (b) change in the platform's service level; (c) change in product price; (d) change in product sales.

\subsection{Analysis on Carbon Emission per Unit Product of Online} and Offline Mode. Based on the parameters' value set at the beginning of Section 6, we make Figure 5(a) showing the change of the manufacturer's carbon emission per unit product of the online and offline mode with the commission rate, in which $\gamma>\left(2 \beta /\left(4 d_{1} \beta-d_{2}^{2}\right)\right)$ holds. For further comparison, we provide two more group values of $\beta, \gamma$, and $d_{2}$. One is $\beta=0.15, \gamma=0.2$, and $d_{2}=1$ so that $\gamma<\left(1 /\left(2 d_{1}\right)\right)$ 


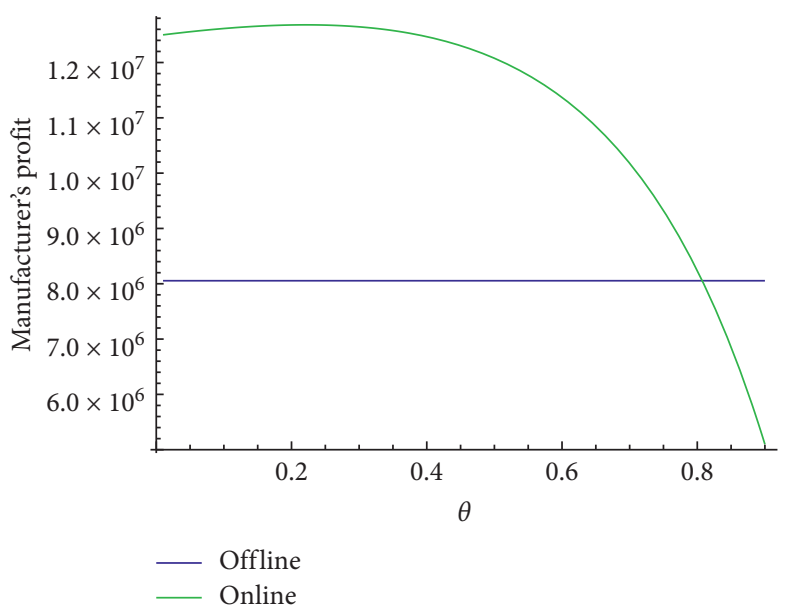

(a)

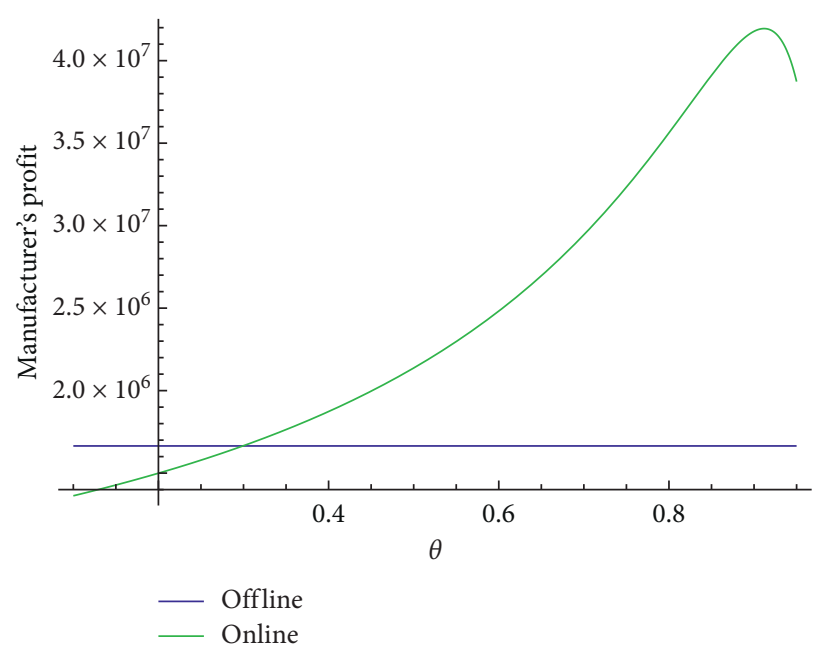

(b)

Figure 4: The manufacturer's profit in the online and offline mode: (a) case 1: $d_{2}^{2}<2 d_{1} \gamma$; (b) case 2: $d_{2}^{2} \geq 2 d_{1} \gamma$.

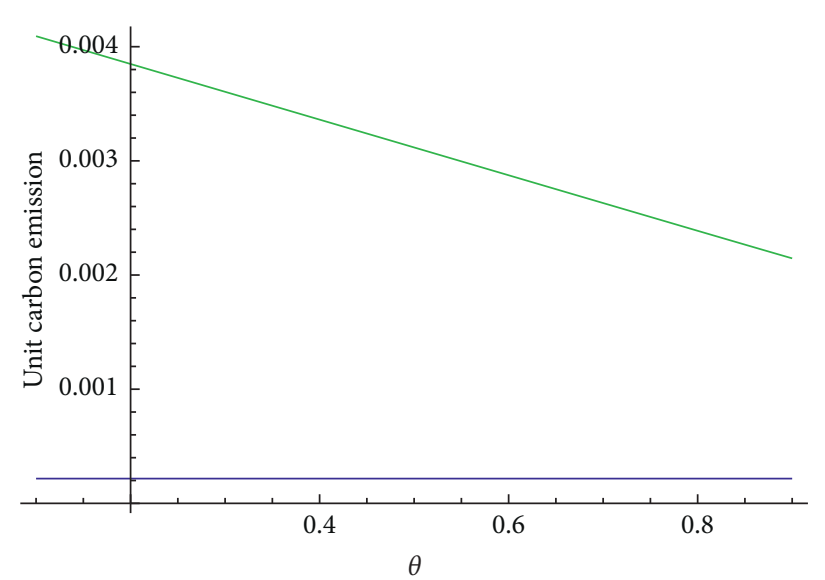

- Offline

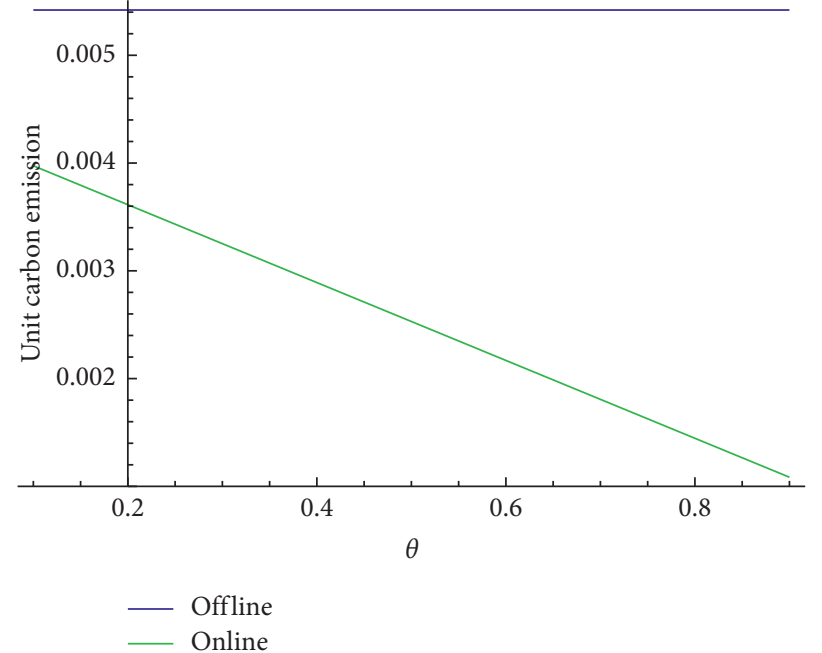

(b)

(a)

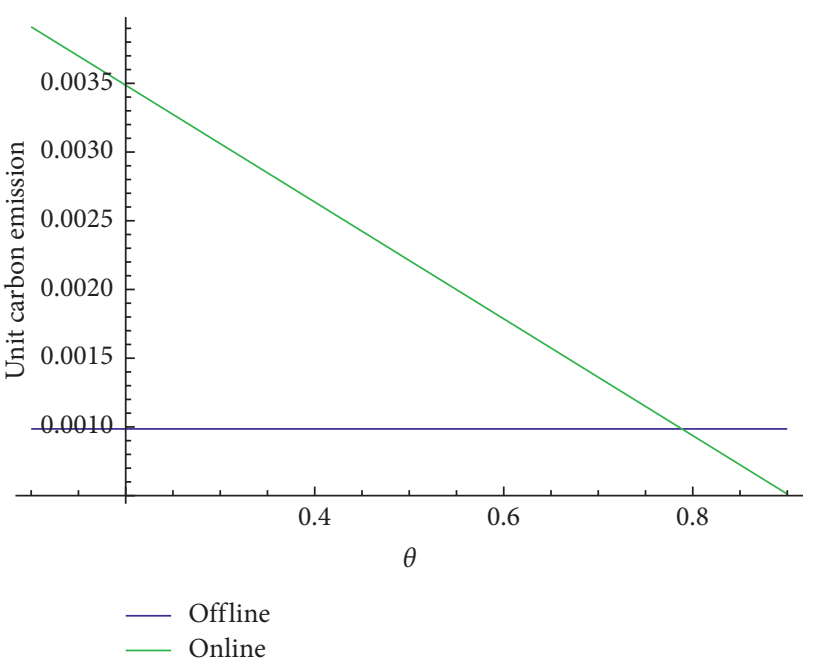

(c)

FIGURE 5: Carbon emission per unit product in the online and offline mode: (a) case $1: \gamma>\left(2 \beta /\left(4 d_{1} \beta-d_{2}^{2}\right)\right)$; (b) case $2: \gamma<\left(1 / 2 d_{1}\right)$; (c) case 3: $\left(1 / 2 d_{1}\right) \leq \gamma \leq\left(2 \beta /\left(4 d_{1} \beta-d_{2}^{2}\right)\right)$. 
is satisfied, and then we make Figure 5(b); another is $\beta=1$, $\gamma=1.1$, and $d_{2}=2.8$, meeting $\left(1 /\left(2 d_{1}\right)\right) \leq \gamma \leq(2 \beta /$ $\left.\left(4 d_{1} \beta-d_{2}^{2}\right)\right)$, and we make Figure 5(c).

Figure 5(a) demonstrates that under the condition $\gamma>\left(2 \beta /\left(4 d_{1} \beta-d_{2}^{2}\right)\right)$, the offline mode produces lower carbon emission per unit product. As mentioned earlier, this case corresponds to products relying on offline experiences and needing much promotion efforts. The online channel, although convenient, is not omnipotent and not suitable for all kinds of product sales. Figure 5(b) depicts the case for products with low sales cost, in which both the elastic coefficient of service cost in the online mode and the promotion effort level coefficient in the offline mode become smaller, so the influence of the service on sales falls down. The e-commerce is applicable for selling this kind of goods. The sudden rise of Pinduoduo is similar to this situation. In Figure 5(c), the supply chains have large space to adjust their carbon emissions per unit product. The online mode has the same carbon emission per unit product as the offline one when $\theta=0.79$, before which the offline mode has lower unit emission and after which the online mode shows its advantages.

However, all these three figures imply that, no matter what the case is, the platform will provide good service with the rise of the commission rate to attract consumers and raise product sales. The platform's behavior has led to good results so that the online mode could cause a continual decrease in unit emission. Therefore, we can adjust the supply chain to the state as we expect by changing the commission rate between the manufacturer and the e-commerce platform properly.

\section{Conclusions}

This research investigates the low-carbon product manufacturer's supply chain channel decision between the online and offline mode when there is a carbon trading market. The offline supply chain mode consists of one manufacturer and one retailer, in which the former is the leader. In comparison, the online one compromises one manufacturer and one e-commerce platform, with the former being the follower. The manufacturer could get profitable by selling its low-carbon products in the product market and trading its carbon quota to cover its emission reduction cost in the carbon market. We reach the following conclusions with practical value.

First, the carbon market establishment is conducive to the manufacturer's carbon emission reduction, especially for those sensitive to the carbon price and those with many emissions currently. The carbon market trading mechanism could motivate manufacturers much to reduce carbon emission. However, some industries with a large carbon emission base and some manufacturers with a high elastic coefficient of carbon emission reduction cost are still facing many challenges. Governments should provide subsidies moderately to increase their initiative. Furthermore, to be more conducive to emission reduction, the manufacturers' necessary condition to be profitable from the carbon market is that the carbon market scale should not be too small. Thus, it comes to that carbon trading market mechanism is not universally applicable. Only in proper carbon market scale interval can manufacturers be motivated.

Second, when manufacturers select the supply chain sales channel between the online mode and offline mode, they have to, on the one hand, experience the status change and, on the other hand, weigh their profit gain or loss. In the online mode, the commission rate represents the manufacturer's power in the supply chain. A low commission rate makes the manufacturer have more profit than the platform, while a high one benefits the platform. As manufacturers are concerned, whether they could select the online mode to gain more profit depends on the property of products they are producing. If consumers are not sensitive to the sales service, manufacturers must fight for a low commission rate; otherwise, if consumers take the service level seriously, the e-commerce platform should provide better service. Highquality service from the platform could help the supply chain gain more profit as a whole. Hence, even though the commission rate has risen to a little high level, the manufacturer can still enter the online mode.

Third, which channel is conducive to carbon emission reduction between the online and offline mode depends on the product type. For daily goods from large-scale mass production, the platform can make full use of its convenience to sell more products, making the online mode help reduce emissions. For goods needing experiencing in person, the offline channel works better than the online one. For products between these above two types, the platform can raise the commission rate properly. After getting more profits, it will improve its service level, making the online supply chain mode conducive to reducing emissions in the same way.

However, there are still some limitations in our models to be further addressed. If consumers prefer low-carbon products, the low-carbon level of products might affect their purchase desire, which affects the product demand in the end [42]. Then, to what extent will this influence the demand and would this change the supply chain member's decision behavior? This research will combine the product market and the carbon trading market better.

\section{Appendix}

\section{A. Proof of Conclusion 1}

We get the optimal decision of this model by the backward induction method. In expression (12), the Hessian matrix of $\Pi_{r 1}$ with respect to $P_{r}$ and $L_{r}$ is

$$
H_{1}=\left[\begin{array}{cc}
\frac{\partial^{2} \Pi_{r 1}}{\partial P_{r}^{2}} & \frac{\partial^{2} \Pi_{r 1}}{\partial P_{r} \partial L_{r}} \\
\frac{\partial^{2} \Pi_{r 1}}{\partial L_{r} \partial P_{r}} & \frac{\partial^{2} \Pi_{r 1}}{\partial L_{r}^{2}}
\end{array}\right]=\left[\begin{array}{cc}
-2 d_{1} & d_{2} \\
d_{2} & -2 \gamma
\end{array}\right] .
$$

It is easy to see $H_{1}$ is the negative definite matrix. 
Let $\left(\partial \Pi_{r 1} / \partial P_{r}\right)=0$ and $\left(\partial \Pi_{r 1} / \partial L_{r}\right)=0$. Solve these simultaneous equations, and then we can obtain the reaction functions of $P_{r}$ and $L_{r}$ as follows:

$$
\begin{aligned}
& P_{r}^{*}=\frac{2 Q \gamma+\left(2 d_{1} \gamma-d_{2}^{2}\right) P_{w}}{4 d_{1} \gamma-d_{2}^{2}}, \\
& L_{r}^{*}=\frac{d_{2}\left(Q-d_{1} P_{w}\right)}{4 d_{1} \gamma-d_{2}^{2}} .
\end{aligned}
$$

Substitute them into expression (11) and let $\left(\partial \Pi_{m 1} / \partial P_{w}\right)=0$ and $\left(\partial \Pi_{m 1} / \partial E\right)=0$; then, we can reach the manufacturer's optimal wholesale price and carbon emission level.

\section{B. Proof of Conclusion 4}

(i) It follows from Conclusions 1 and 2 that the manufacturer's emissions in two modes are

$$
E_{1}^{*}=E_{2}^{*}=\frac{2 \widehat{E} \alpha+\Phi}{2(\alpha+\varphi)} \text {. }
$$

Then, its carbon emission reduction is

$$
\Delta E=\widehat{E}-\frac{2 \widehat{E} \alpha+\Phi}{2(\alpha+\varphi)}=\frac{2 \widehat{E} \phi-\Phi}{2(\alpha+\varphi)} .
$$

Based on the hypothesis in Section 3, $\varphi \widehat{E}-\Phi>0$.

Thus, $\Delta E>0$; that is, $E_{1}^{*}=E_{2}^{*}<\widehat{E}$.

(ii) It is derived easily from the expression of $\Delta E$ that it increases monotonously with $\widehat{E}$ and $\varphi$ and decreases monotonously with $\Phi$ and $\alpha$.

\section{Proof of Conclusion 5}

According to the above conclusions, the manufacturer's profit in the carbon market is

$$
I_{m 1 c}^{*}=I_{m 2 c}^{*}=\frac{\Phi^{2}+4 \alpha \widehat{E}(\Phi-\varphi \widehat{E})}{4(\alpha+\varphi)} .
$$
$\Phi$

We take the numerator of this fraction as the function of

$$
f(\Phi)=\Phi^{2}+4 \alpha \widehat{E}(\Phi-\varphi \widehat{E}) .
$$

Then, $f(\Phi)$ is a parabola pointing upward with two intercepts on the $\Phi$ axis, $\Phi_{1}=-2 \alpha \widehat{E}(\sqrt{((1+\varphi) / \alpha)}+1)$ and $\Phi_{2}=2 \alpha \widehat{E}(\sqrt{((1+\varphi) / \alpha)}-1)$.

Because $\Phi<0$, we have that the manufacturer's profit in the carbon market is negative if $0<(\Phi / \widehat{E})<2 \alpha(\sqrt{((1+\varphi) / \alpha)}-1)$ and positive if $(\Phi / \widehat{E})>2 \alpha(\sqrt{((1+\varphi) / \alpha)}-1)$.

Moreover, in the carbon market, $\Phi-\varphi \widehat{E}<0$. This conclusion holds.

\section{Proof of Conclusion 6}

(i) $P^{*}=\left(2 Q \beta /\left(4 d_{1} \beta-d_{2}^{2} \theta\right)\right)+(C /(2(1-\theta)))$.

It is obvious that both $\left(2 Q \beta /\left(4 d_{1} \beta-d_{2}^{2} \theta\right)\right)$ and $(C /(2(1-\theta)))$ increase with $\theta$.

Thus, $P$ increases with $\theta$.

(ii) $L_{p}^{*}=\left(d_{2} Q \theta /\left(4 d_{1} \beta-d_{2}^{2} \theta\right)\right)$.

Since $4 d_{1} \beta-d_{2}^{2} \theta>0$, it is obvious that $L_{p}^{*}$ increases with $\theta$.

(iii) $\Pi_{p 2}^{*}=\left(\left(\theta\left[4 Q^{2} \beta(1-\theta)^{2}-C^{2} d_{1}\left(4 d_{1} \beta-d_{2}^{2} \theta\right)\right]\right) /(4\right.$

$\left.\left.(1-\theta)^{2}\left(4 d_{1} \beta-d_{2}^{2} \theta\right)\right)\right)=\theta\left[\left(Q^{2} \beta /\left(4 d_{1} \beta-d_{2}^{2} \theta\right)\right)-\right.$

$\left.\left(C^{2} d_{1} /\left(4(1-\theta)^{2}\right)\right)\right]$.

Because $Q$ is a large enough positive number, we only consider terms with $Q^{2}$, that is, $\left(Q^{2} \beta \theta /\left(4 d_{1} \beta-d_{2}^{2} \theta\right)\right)$, which increases with $\theta$.

(iv) The manufacturer's total profit

$\Pi_{m 2}^{*}=\left(\left(d_{1}\left[4 Q \beta(1-\theta)-C\left(4 d_{1} \beta-d_{2}^{2} \theta\right)\right]^{2}\right) /(4(1\right.$

$\left.\left.-\theta)\left(4 d_{1} \beta-d_{2}^{2} \theta\right)^{2}\right)\right)+\left(\left(\Phi^{2}+4 \alpha \widehat{E}(\Phi-\varphi \widehat{E})\right) /\right.$

$4(\alpha+\varphi))$.

We represent the manufacturer's profit in the product market as

$$
\Pi_{m 21}^{*}=\frac{d_{1}\left[4 Q \beta(1-\theta)-C\left(4 d_{1} \beta-d_{2}^{2} \theta\right)\right]^{2}}{4(1-\theta)\left(4 d_{1} \beta-d_{2}^{2} \theta\right)^{2}} .
$$

Then,

$$
\begin{aligned}
\Pi_{m 21}^{*} & =\frac{d_{1}\left[4 Q \beta(1-\theta)-C\left(4 d_{1} \beta-d_{2}^{2} \theta\right)\right]^{2}}{4(1-\theta)\left(4 d_{1} \beta-d_{2}^{2} \theta\right)^{2}} \\
& =d_{1}\left[\frac{4 Q^{2} \beta^{2}(1-\theta)}{\left(4 d_{1} \beta-d_{2}^{2} \theta\right)^{2}}-\frac{2 C Q \beta}{4 d_{1} \beta-d_{2}^{2} \theta}+\frac{C^{2}}{4(1-\theta)}\right] .
\end{aligned}
$$

Because $Q$ is a large enough positive number, we only consider terms with $Q^{2}$, that is, $\left(\left(4 Q^{2} \beta^{2}(1-\theta)\right) /\left(4 d_{1} \beta-d_{2}^{2} \theta\right)^{2}\right)$.

Let $f(\theta)=\left(\left(\beta^{2}(1-\theta)\right) /\left(\left(4 d_{1} \beta-d_{2}^{2} \theta\right)^{2}\right)\right)$, then

$$
\frac{\mathrm{d} f(\theta)}{\mathrm{d} \theta}=-\frac{\beta^{2}\left[\left(4 d_{1} \beta-d_{2}^{2}\right)-(1-\theta) d_{2}^{2}\right]}{\left(4 d_{1} \beta-d_{2}^{2}\right)^{3}} .
$$

Because when $\quad d_{2}^{2}<2 d_{1} \beta, \quad(\mathrm{d} f(\theta) / \mathrm{d} \theta)<0$, $\left(4 d_{1} \beta-d_{2}^{2}\right)-(1-\theta) d_{2}^{2} \in\left(4 d_{1} \beta-2 d_{2}^{2}, 4 d_{1} \beta-d_{2}^{2}\right)$, meaning that $\Pi_{m 2}^{*}$ decreases with $\theta$; when $d_{2}^{2}>2 d_{1} \beta$, 


$$
\begin{gathered}
\left(4 d_{1} \beta-d_{2}^{2}\right)-(1-\theta) d_{2}^{2} \in\left(4 d_{1} \beta-2 d_{2}^{2}, 0\right) \\
\cup\left[0,4 d_{1} \beta-d_{2}^{2}\right)
\end{gathered}
$$

(v) The supply chain's profit

indicating that $\Pi_{m 2}^{*} \Pi_{m 2}^{*}$ first increases and then decreases with $\theta$.

$$
\begin{aligned}
& \Pi_{2}=\frac{4 Q^{2} \beta^{2} d_{1}(1-\theta)}{\left(4 d_{1} \beta-d_{2}^{2} \theta\right)^{2}}+\frac{d_{1} C^{2}(1-2 \theta)}{4(1-\theta)^{2}}+\frac{\left(Q \theta-2 d_{1} C\right) Q \beta}{4 d_{1} \beta-d_{2}^{2} \theta}+\frac{\Phi^{2}+4 \alpha \widehat{E}(\Phi-\varphi \widehat{E})}{4(\alpha+\varphi)} \\
&=\frac{4 Q^{2} \beta^{2} d_{1}(1-\theta)+\left(Q \theta-2 d_{1} C\right) Q \beta\left(4 d_{1} \beta-d_{2}^{2} \theta\right)}{\left(4 d_{1} \beta-d_{2}^{2} \theta\right)^{2}}+\frac{d_{1} C^{2}(1-2 \theta)}{4(1-\theta)^{2}}+\frac{\Phi^{2}+4 \alpha \widehat{E}(\Phi-\varphi \widehat{E})}{4(\alpha+\varphi)} \\
&=\frac{4 d_{1} \beta-d_{2}^{2} \theta^{2}}{\left(4 d_{1} \beta-d_{2}^{2} \theta\right)^{2}} Q^{2} \beta+\frac{2 C d_{1} d_{2}^{2} \theta-8 C d_{1}^{2} \beta}{\left(4 d_{1} \beta-d_{2}^{2} \theta\right)^{2}} Q \beta+\frac{d_{1} C^{2}(1-2 \theta)}{4(1-\theta)^{2}}+\frac{\Phi^{2}+4 \alpha \widehat{E}(\Phi-\varphi \widehat{E})}{4(\alpha+\varphi)} . \\
& d_{2}^{2} \theta^{2}-8 d_{1} \beta \theta+4 d_{1} \beta<0 .
\end{aligned}
$$

Let $f(\theta)=\left(\left(4 d_{1} \beta-d_{2}^{2} \theta^{2}\right) /\left(4 d_{1} \beta-d_{2}^{2} \theta\right)^{2}\right)$, then

$$
\frac{\mathrm{d} f(\theta)}{\mathrm{d} \theta}=\frac{8 d_{1} d_{2}^{2} \beta(1-\theta)}{\left(4 d_{1} \beta-d_{2}^{2} \theta\right)^{3}}>0 \text {. }
$$

Since $Q$ is a large enough positive number, $\Pi_{2}$ increases with $\theta$.

\section{E. Proof of Conclusion 8}

The manufacturer's profit in the product market is

$$
I_{m 2 p}^{*}=\frac{d_{1}\left[4 Q \beta(1-\theta)-C\left(4 d_{1} \beta-d_{2}^{2} \theta\right)\right]^{2}}{4(1-\theta)\left(4 d_{1} \beta-d_{2}^{2} \theta\right)^{2}} .
$$

The platform's profit in the product market is

$$
\Pi_{p 2}^{*}=\frac{\theta\left[4 Q^{2} \beta(1-\theta)^{2}-C^{2} d_{1}\left(4 d_{1} \beta-d_{2}^{2} \theta\right)\right]}{4(1-\theta)^{2}\left(4 d_{1} \beta-d_{2}^{2} \theta\right)} .
$$

Since $Q$ is a large enough positive number, we only compare terms of $Q$ with the highest power (square) during the comparison of their profit difference in the product market. We denote them by $\widehat{I}_{m 2 p}$ and $\widehat{\Pi}_{p 2}^{*}$, respectively; then,

$$
\begin{aligned}
\widehat{I}_{m 2 p}^{*} & =\frac{16 d_{1} Q^{2} \beta^{2}(1-\theta)^{2}}{4(1-\theta)\left(4 d_{1} \beta-d_{2}^{2} \theta\right)^{2}} \\
& =\frac{4 d_{1} \beta(1-\theta)}{\left(4 d_{1} \beta-d_{2}^{2} \theta\right) \theta} \cdot \frac{Q^{2} \beta \theta}{4 d_{1} \beta-d_{2}^{2} \theta}, \\
\widehat{\Pi}_{p 2}^{*} & =\frac{Q^{2} \beta \theta}{4 d_{1} \beta-d_{2}^{2} \theta} .
\end{aligned}
$$

The necessary condition for $\widehat{I}_{m 2 p}^{*}<\widehat{\Pi}_{p 2}^{*}$ is that
Solve the follow equation with respect to $\theta$

$$
d_{2}^{2} \theta^{2}-8 d_{1} \beta \theta+4 d_{1} \beta=0
$$

Then, we have $\theta=\left(\left(4 d_{1} \beta \pm 2 \sqrt{d_{1} \beta\left(4 d_{1} \beta-d_{2}^{2}\right)}\right) / d_{2}^{2}\right)$. Therefore, $\widehat{I}_{m 2 p}^{*}<\widehat{\Pi}_{p 2}$ if

$$
\frac{4 d_{1} \beta-2 \sqrt{d_{1} \beta\left(4 d_{1} \beta-d_{2}^{2}\right)}}{d_{2}^{2}}<\theta<\frac{4 d_{1} \beta+2 \sqrt{d_{1} \beta\left(4 d_{1} \beta-d_{2}^{2}\right)}}{d_{2}^{2}} .
$$

However,

$$
\frac{4 d_{1} \beta+2 \sqrt{d_{1} \beta\left(4 d_{1} \beta-d_{2}^{2}\right)}}{d_{2}^{2}}>1 .
$$
$<\theta<1$.

Thus, $\widehat{I}_{m 2 p}^{*}<\widehat{\Pi}_{p 2}^{*}$ if $\left(\left(4 d_{1} \beta-2 \sqrt{d_{1} \beta\left(4 d_{1} \beta-d_{2}^{2}\right.}\right) / d_{2}^{2}\right)$

\section{F. Proof of Conclusion 9}

It follows from the above conclusions that

$$
\begin{aligned}
\Pi_{m 1}^{*}= & \frac{\left(Q-C d_{1}\right)^{2} \gamma}{2\left(4 d_{1} \gamma-d_{2}^{2}\right)}+\frac{\Phi^{2}+4 \alpha \widehat{E}(\Phi-\varphi \widehat{E})}{4(\alpha+\varphi)} \\
\Pi_{m 2}^{*}= & \frac{d_{1}\left[4 Q \beta(1-\theta)-C\left(4 d_{1} \beta-d_{2}^{2} \theta\right)\right]^{2}}{4(1-\theta)\left(4 d_{1} \beta-d_{2}^{2} \theta\right)^{2}} \\
& +\frac{\Phi^{2}+4 \alpha \widehat{E}(\Phi-\varphi \widehat{E})}{4(\alpha+\varphi)}
\end{aligned}
$$

$\Pi_{m 1}^{*}$ and $\Pi_{m 2}^{*}$ have the same profit in the carbon trading market, so we only compare their profits in the product market. And, since $Q$ is a large enough positive number, we 
only compare terms of $Q$ with the highest power (square).

Further,

We denote them by $\widehat{\Pi}_{m 1}^{*}$ and $\widehat{\Pi}_{m 2}$, respectively; then,

$$
\begin{aligned}
& \widehat{\Pi}_{m 1}^{*}=\frac{Q^{2} \gamma}{2\left(4 d_{1} \gamma-d_{2}^{2}\right)}, \\
& \widehat{\Pi}_{m 2}^{*}=\frac{16 d_{1} Q^{2} \beta^{2}(1-\theta)^{2}}{4(1-\theta)\left(4 d_{1} \beta-d_{2}^{2} \theta\right)^{2}} .
\end{aligned}
$$

$$
\begin{aligned}
\widehat{\Pi}_{m 2}^{*} & =\frac{16 d_{1} Q^{2} \beta^{2}(1-\theta)^{2}}{4(1-\theta)\left(4 d_{1} \beta-d_{2}^{2} \theta\right)^{2}}=\frac{4 d_{1} \beta(1-\theta)}{\left(4 d_{1} \beta-d_{2}^{2} \theta\right) \theta} \cdot \frac{Q^{2} \beta \theta}{4 d_{1} \beta-d_{2}^{2} \theta} \\
& =\frac{4 d_{1} Q^{2} \beta^{2}(1-\theta)}{\left(4 d_{1} \beta-d_{2}^{2} \theta\right)^{2}}=\frac{Q^{2} \gamma}{2\left(4 d_{1} \gamma-d_{2}^{2}\right)} \cdot \frac{8 d_{1} \beta^{2}(1-\theta)\left(4 d_{1} \gamma-d_{2}^{2}\right)}{\gamma\left(4 d_{1} \beta-d_{2}^{2} \theta\right)^{2}} \\
& =\widehat{\Pi}_{m 1}^{*} \times \frac{8 d_{1} \beta^{2}(1-\theta)\left(4 d_{1} \gamma-d_{2}^{2}\right)}{\gamma\left(4 d_{1} \beta-d_{2}^{2} \theta\right)^{2}} .
\end{aligned}
$$

The necessary condition to gain more profit in the online mode is

$$
\frac{8 d_{1} \beta^{2}(1-\theta)\left(4 d_{1} \gamma-d_{2}^{2}\right)}{\gamma\left(4 d_{1} \beta-d_{2}^{2} \theta\right)^{2}}>1 .
$$

After simplifying the inequality, we have $\gamma d_{2}^{4} \theta^{2}-8 d_{1} \beta\left[(\beta+\gamma) d_{2}^{2}-4 d_{1} \beta \gamma\right] \theta+8 d_{1} \beta^{2}\left(d_{2}^{2}-2 d_{1} \gamma\right)<0$.

Let

$$
\begin{aligned}
f(\theta)= & \gamma d_{2}^{4} \theta^{2}-8 d_{1} \beta(\beta+\gamma)\left(d_{2}^{2}-4 d_{1} \frac{\beta \gamma}{\beta+\gamma}\right) \theta \\
& +8 d_{1} \beta^{2}\left(d_{2}^{2}-2 d_{1} \gamma\right) .
\end{aligned}
$$

Then, it is a parabola with respect to $\theta$, going upward. It is obvious that $4 d_{1}(\beta \gamma /(\beta+\gamma))<2 d_{1} \gamma$.

(i) if $d_{2}^{2}<4 d_{1}(\beta \gamma /(\beta+\gamma))<2 d_{1} \gamma$

In this case, the axis of symmetry of $f(\theta)$ is negative, its intercept on the vertical axis is negative, and among its two intercepts on the horizontal axis, one is positive and another is negative. Thus,

$$
\theta \in\left[0, \min \left\{\theta_{2}, 1\right\}\right]
$$

(ii) If $4 d_{1}(\beta \gamma /(\beta+\gamma))<d_{2}^{2}<2 d_{1} \gamma$

In this case, the axis of symmetry of $f(\theta)$ is positive, its intercept on the vertical axis is negative, and among its two intercepts on the horizontal axis, one is positive and another is negative. Thus,

$$
\theta \in\left[0, \min \left\{\theta_{2}, 1\right\}\right]
$$

(iii) if $4 d_{1}(\beta \gamma /(\beta+\gamma))<2 d_{1} \gamma<d_{2}^{2}$

In this case,

$$
\begin{aligned}
\Delta & =64 d_{1}^{2} \beta^{2}\left[(\beta+\gamma) d_{2}^{2}-4 d_{1} \beta \gamma\right]^{2}-32 d_{1} d_{2}^{4} \beta^{2} \gamma\left(d_{2}^{2}-2 d_{1} \gamma\right) \\
& =32 d_{1} \beta^{2}\left\{2 d_{1}\left[(\beta+\gamma) d_{2}^{2}-4 d_{1} \beta \gamma\right]^{2}-d_{2}^{4} \gamma\left(d_{2}^{2}-2 d_{1} \gamma\right)\right\} .
\end{aligned}
$$

Let

$$
\Delta_{1}=2 d_{1}\left[(\beta+\gamma) d_{2}^{2}-4 d_{1} \beta \gamma\right]^{2}-d_{2}^{4} \gamma\left(d_{2}^{2}-2 d_{1} \gamma\right) .
$$

Then,

$$
\begin{aligned}
\Delta_{1}= & 2 d_{1}\left[(\beta+\gamma) d_{2}^{2}-4 d_{1} \beta \gamma\right]^{2}-d_{2}^{4} \gamma\left(d_{2}^{2}-2 d_{1} \gamma\right) \\
= & 2 d_{1}\left[\beta\left(d_{2}^{2}-2 d_{1} \gamma\right)+\gamma\left(d_{2}^{2}-2 d_{1} \beta\right)\right]^{2}-d_{2}^{4} \gamma\left(d_{2}^{2}-2 d_{1} \gamma\right) \\
= & 2 d_{1} \beta^{2}\left(d_{2}^{2}-2 d_{1} \gamma\right)^{2}+\gamma\left[4 d_{1} \beta\left(d_{2}^{2}-2 d_{1} \beta\right)\right. \\
& \left.-d_{2}^{4}\right]\left(d_{2}^{2}-2 d_{1} \gamma\right)+2 d_{1} \gamma^{2}\left(d_{2}^{2}-2 d_{1} \beta\right)^{2} .
\end{aligned}
$$

Hence, $\Delta_{1}$ is a parabola with respect to $\left(d_{2}^{2}-2 d_{1} \gamma\right)$, going upward. Its axis of symmetry is 


$$
\begin{aligned}
& -\frac{\gamma\left[4 d_{1} \beta\left(d_{2}^{2}-2 d_{1} \beta\right)-d_{2}^{4}\right]}{4 d_{1} \beta^{2}} \\
& =\frac{\gamma}{4 d_{1} \beta^{2}}\left[\left(d_{2}^{2}-2 d_{1} \beta\right)^{2}+4\left(d_{1} \beta\right)^{2}\right]>0 .
\end{aligned}
$$

The discriminant of the quadratic equation corresponding to this parabola is

$$
\begin{aligned}
\Delta_{2} & =\gamma^{2}\left[4 d_{1} \beta\left(d_{2}^{2}-2 d_{1} \beta\right)-d_{2}^{4}\right]^{2}-16 d_{1}^{2} \beta^{2} \gamma^{2}\left(d_{2}^{2}-2 d_{1} \beta\right)^{2} \\
& =d_{2}^{8} \gamma^{2}-8 d_{1} d_{2}^{4} \beta \gamma^{2}\left(d_{2}^{2}-2 d_{1} \beta\right) \\
& =d_{2}^{4} \gamma^{2}\left(d_{2}^{2}-4 d_{1} \beta\right)^{2}>0,
\end{aligned}
$$

which means that $\Delta_{1}$ has two intersections on the horizontal axis. It is easy to obtain the smaller one is

$$
d_{2}^{2}-2 d_{1} \gamma=4 d_{1} \gamma
$$

However, $d_{2}^{2}<4 d_{1} \gamma$; that is, $d_{2}^{2}-2 d_{1} \gamma<2 d_{1} \gamma$. Therefore, within the range, $\Delta_{1}$ is always positive; that is, $\Delta>0$. It follows that $f(\theta)$ has two intersections on the horizontal axis. And, both the axis of symmetry and intercept on the vertical axis of $f(\theta)$ are positive. Its two intercepts on the horizontal axis are positive. Here, $d_{2}^{2} \leq 4 d_{1} \gamma$, so $d_{2}^{2} \gamma \leq 4 d_{1} \gamma^{2}$. Then,

$$
\begin{aligned}
& 8 d_{1} \beta\left[(\beta+\gamma) d_{2}^{2}-4 d_{1} \beta \gamma\right]-2 \gamma d_{2}^{4} \\
& =2 \gamma d_{2}^{2}\left(4 d_{1} \beta-d_{2}^{2}\right)-8 d_{1} \beta^{2}\left(4 d_{1} \gamma-d_{2}^{2}\right) \\
& <8 d_{1} \gamma^{2}\left(4 d_{1} \beta-d_{2}^{2}\right)-8 d_{1} \beta^{2}\left(4 d_{1} \gamma-d_{2}^{2}\right) \\
& =8 d_{1}(\gamma-\beta)\left[4 d_{1} \beta \gamma-d_{2}^{2}(\gamma+\beta)\right] \\
& <0
\end{aligned}
$$

and $8 d_{1} \beta\left[(\beta+\gamma) d_{2}^{2}-4 d_{1} \beta \gamma\right]<2 \gamma d_{2}^{4}$, namely, $\theta_{1}<1$. Thus, $\theta \in\left[\theta_{1}, \min \left\{\theta_{2}, 1\right\}\right]$. Based on the above analysis, Conclusion 9 holds.

\section{G. Proof of Conclusion 10}

It follows from Conclusion 1 and 2 that the online channel produces the same carbon emission as the offline one. We only need to compare the demand in these two modes.

$$
\begin{aligned}
q_{1} & =\left(Q-C d_{1}\right) d_{1} \gamma=Q d_{1} \gamma-C d_{1}^{2} \gamma, \\
q_{2} & =\frac{2 \beta}{4 d_{1} \beta-\theta d_{2}^{2}} Q d_{1}-\frac{C d_{1}}{2(1-\theta)}, \\
& \frac{2 \beta}{4 d_{1} \beta-\theta d_{2}^{2}} \in\left(\frac{1}{2 d_{1}}, \frac{2 \beta}{4 d_{1} \beta-d_{2}^{2}}\right), \quad 0<\theta<1 .
\end{aligned}
$$

Based on the fact that $Q$ is a large enough positive number, after comparing the expression of $q_{1}$ and $q_{2}$, we have

$$
\begin{aligned}
& q_{1}<q_{2}, \quad \text { if } \gamma<\frac{1}{2 d_{1}}, \\
& q_{1}>q_{2}, \quad \text { if } \gamma>\frac{2 \beta}{4 d_{1} \beta-d_{2}^{2}},
\end{aligned}
$$

$q_{1}>q_{2}$ in the beginning and then $q_{1}<q_{2}$ if $\left(1 / 2 d_{1}\right) \leq \gamma \leq\left(2 \beta /\left(4 d_{1} \beta-d_{2}^{2}\right)\right)$. Thus, Conclusion 10 holds.

\section{Data Availability}

The data used to support the findings of this research are included within this paper.

\section{Conflicts of Interest}

The authors declare that they have no conflicts of interest.

\section{Acknowledgments}

This paper was supported financially by the Philosophy and Social Science Project of Shandong Province (19BJCJ12).

\section{References}

[1] Y. Wang, Z. Yu, and L. Shen, "Study on the decision-making and coordination of an e-commerce supply chain with manufacturer fairness concerns," International Journal of Production Research, vol. 57, no. 9, pp. 2788-2808, 2019.

[2] Y. Wang, R. Fan, L. Shen, and W. Miller, "Recycling decisions of low-carbon e-commerce closed-loop supply chain under government subsidy mechanism and altruistic preference," Journal of Cleaner Production, vol. 259, Article ID 120883, 2020.

[3] D. Zhou, X. Liang, Y. Zhou, and K. Tang, "Does emission trading boost carbon productivity? Evidence from China's pilot emission trading scheme," International Journal of Environmental Research and Public Health, vol. 17, no. 15, p. 5522, 2020.

[4] D. Nong, S. Meng, and M. Siriwardana, "An assessment of a proposed ETS in Australia by using the MONASH-Green model," Energy Policy, vol. 108, pp. 281-291, 2017.

[5] I. Diaz-Rainey and D. J. Tulloch, "Carbon pricing and system linking: lessons from the New Zealand emissions trading scheme," Energy Economics, vol. 73, pp. 66-79, 2018.

[6] J. Jaraite and C. Di Maria, "Did the EU ETS make a difference? An empirical assessment using Lithuanian firm-level data," Energy Journal, vol. 37, no. 1, pp. 1-23, 2016.

[7] S. Benjaafar, Y. Li, and M. Daskin, "Carbon footprint and the management of supply chains: insights from simple models," IEEE Transactions on Automation Science and Engineering, vol. 10, no. 1, pp. 99-116, 2013.

[8] X. Xu, P. He, H. Xu, and Q. Zhang, "Supply chain coordination with green technology under cap-and-trade regulation," International Journal of Production Economics, vol. 183, pp. 433-442, 2017.

[9] B. Cheng, H. Dai, P. Wang, D. Zhao, and T. Masui, "Impacts of carbon trading scheme on air pollutant emissions in Guangdong province of China," Energy for Sustainable Development, vol. 27, pp. 174-185, 2015.

[10] C. Springer, S. Evans, J. Lin, and D. Roland-Holst, "Low carbon growth in China: the role of emissions trading in a 
transitioning economy," Applied Energy, vol. 235, pp. 11181125, 2019.

[11] Y. Hu, S. Ren, Y. Wang, and X. Chen, "Can carbon emission trading scheme achieve energy conservation and emission reduction? Evidence from the industrial sector in China," Energy Economics, vol. 85, Article ID 104590, 2020.

[12] Y. Zhang, S. Li, T. Luo, and J. Gao, "The effect of emission trading policy on carbon emission reduction: evidence from an integrated study of pilot regions in China," Journal of Cleaner Production, vol. 265, Article ID 121843, 2020.

[13] L. Liu, C. Chen, Y. Zhao, and E. Zhao, "China's carbonemissions trading: overview, challenges and future," Renewable and Sustainable Energy Reviews, vol. 49, pp. 254-266, 2015.

[14] J. Jiang, D. Xie, B. Ye, B. Shen, and Z. Chen, "Research on China's cap-and-trade carbon emission trading scheme: overview and outlook," Applied Energy, vol. 178, pp. 902-917, 2016.

[15] A. Caparrós, J.-C. Péreau, and T. Tazdaït, "Emission trading and international competition: the impact of labor market rigidity on technology adoption and output," Energy Policy, vol. 55, pp. 36-43, 2013.

[16] Y. Cheng, D. Mu, and Y. Zhang, "Mixed carbon policies based on cooperation of carbon emission reduction in supply chain," Discrete Dynamics in Nature and Society, vol. 2017, Article ID 4379124, 11 pages, 2017.

[17] W. T. Chen, Y. P. Li, G. H. Huang, X. Chen, and Y. F. Li, “A two-stage inexact-stochastic programming model for planning carbon dioxide emission trading under uncertainty," Applied Energy, vol. 87, no. 3, pp. 1033-1047, 2010.

[18] Q. Pang, M. Li, T. Yang, and Y. Shen, "Supply chain coordination with carbon trading price and consumers' environmental awareness dependent demand," Mathematical Problems in Engineering, vol. 2018, Article ID 8749251, 11 pages, 2018.

[19] Z. Wang and Q. Wu, "Carbon emission reduction and product collection decisions in the closed-loop supply chain with cap-and-trade regulation," International Journal of Production Research, vol. 2020, Article ID 1762943, 2020.

[20] L. Xu, C. Wang, and J. Zhao, "Decision and coordination in the dual-channel supply chain considering cap-and-trade regulation," Journal of Cleaner Production, vol. 197, pp. 551561, 2018.

[21] L. Liu, L. Feng, B. Xu, and W. Deng, "Operation strategies for an omni-channel supply chain: who is better off taking on the online channel and offline service?" Electronic Commerce Research and Applications, vol. 39, Article ID 100918, 2020.

[22] A. Dumrongsiri, M. Fan, A. Jain, and K. Moinzadeh, "A supply chain model with direct and retail channels," European Journal of Operational Research, vol. 187, no. 3, pp. 691-718, 2008.

[23] P. He, Y. He, and H. Xu, "Channel structure and pricing in a dual-channel closed-loop supply chain with government subsidy," International Journal of Production Economics, vol. 213, pp. 108-123, 2019.

[24] Y. He, H. Huang, and D. Li, "Inventory and pricing decisions for a dual-channel supply chain with deteriorating products," Operational Research, vol. 20, no. 3, pp. 1461-1503, 2020.

[25] R. Batarfi, M. Y. Jaber, and S. Zanoni, "Dual-channel supply chain: a strategy to maximize profit," Applied Mathematical Modelling, vol. 40, no. 21-22, pp. 9454-9473, 2016.

[26] W. S. Yoo and E. Lee, "Internet channel entry: a strategic analysis of mixed channel structures," Marketing Science, vol. 30, no. 1, pp. 29-41, 2011.
[27] F. Bernstein, J.-S. Song, and X. Zheng, “"Bricks-and-mortar” vs. "clicks-and-mortar": an equilibrium analysis," European Journal of Operational Research, vol. 187, no. 3, pp. 671-690, 2008.

[28] F. Gao and X. Su, "Omnichannel retail operations with buyonline-and-pick-up-in-store," Management Science, vol. 63, no. 8, pp. 2478-2492, 2017.

[29] S. Gallino and A. Moreno, "Integration of online and offline channels in retail: the impact of sharing reliable inventory availability information," Management Science, vol. 60, no. 6, pp. 1434-1451, 2014.

[30] X. Chen, X. Wang, and X. Jiang, “The impact of power structure on the retail service supply chain with an $\mathrm{O} 2 \mathrm{O}$ mixed channel," Journal of the Operational Research Society, vol. 67, no. 2, pp. 294-301, 2016.

[31] X. Jia, "Decision-making of online channels under three power structures," Measurement \& Control, vol. 53, no. 3-4, pp. 296-310, 2020.

[32] H. Li, K. Leng, Q. Qing, and S. X. Zhu, "Strategic interplay between store brand introduction and online direct channel introduction," Transportation Research Part E: Logistics and Transportation Review, vol. 118, pp. 272-290, 2018.

[33] P. Zhang, Y. He, and C. Shi, "Retailer's channel structure choice: online channel, offline channel, or dual channels?" International Journal of Production Economics, vol. 191, pp. 37-50, 2017.

[34] Q. Lu and N. Liu, "Pricing games of mixed conventional and e-commerce distribution channels," Computers \& Industrial Engineering, vol. 64, no. 1, pp. 122-132, 2013.

[35] X. Pu, L. Gong, and X. Han, "Consumer free riding: coordinating sales effort in a dual-channel supply chain," Electronic Commerce Research and Applications, vol. 22, pp. 1-12, 2017.

[36] A. A. Tsay and N. Agrawal, "Channel conflict and coordination in the E-commerce age," Production and Operations Management, vol. 13, no. 1, pp. 93-110, 2004.

[37] Q. Han and Y. Wang, "Decision and coordination in a lowcarbon e-supply chain considering the manufacturer's carbon emission reduction behavior," Sustainability, vol. 10, no. 5, p. 1686, 2018.

[38] Q. Li and B. Li, "Dual-channel supply chain equilibrium problems regarding retail services and fairness concerns," Applied Mathematical Modelling, vol. 40, no. 15-16, pp. 7349-7367, 2016.

[39] Q. Han, Y. Wang, L. Shen, and W. Dong, "Decision and coordination of low-carbon e-commerce supply chain with government carbon subsidies and fairness concerns," Complexity, vol. 2020, Article ID 1974942, 19 pages, 2020.

[40] A. Nair and R. Narasimhan, "Dynamics of competing with quality- and advertising-based goodwill," European Journal of Operational Research, vol. 175, no. 1, pp. 462-474, 2006.

[41] C.-H. Wu, "Price and service competition between new and remanufactured products in a two-echelon supply chain," International Journal of Production Economics, vol. 140, no. 1, pp. 496-507, 2012.

[42] P. He, Y. He, C. Shi, H. Xu, and L. Zhou, "Cost-sharing contract design in a low-carbon service supply chain," Computers \& Industrial Engineering, vol. 139, Article ID 106160, 2020. 